EXHALED MARKERS

\title{
Origin of nitrite and nitrate in nasal and exhaled breath condensate and relation to nitric oxide formation
}

\author{
H Marteus, D C Törnberg, E Weitzberg, U Schedin, K Alving
}

Thorax 2005;60:219-225. doi: 10.1136/thx.2004.030635

See end of article for authors' affiliations

Correspondence to:

Professor K Alving,

Department of Physiology

and Pharmacology,

Karolinska Institutet,

SE-171 77 Stockholm

Sweden; kjell.alving@fyfa.

ki.se

Received 24 June 2004

Accepted

20 September 2004
Background: Raised concentrations of nitrate and nitrite have been found in exhaled breath condensate (EBC) in airway disease, and it has been postulated that this reflects increased nitric oxide (NO) metabolism. However, the chemical and anatomical origin of nitrate and nitrite in the airways has not yet been sufficiently studied.

Methods: The fraction of exhaled $\mathrm{NO}$ at an exhalation flow rate of $50 \mathrm{ml} / \mathrm{s}\left(\mathrm{FE}_{\mathrm{NO}}\right.$ ) and nitrite and nitrate in EBC, nasal condensate, and saliva were measured in 17 tracheostomised and 15 non-tracheostomised subjects, all of whom were non-smokers without respiratory disease. Tracheal and oral samples were taken from the tracheostomised subjects and nasal (during velum closure) and oral samples from the nontracheostomised subjects. Measurements were performed before and after sodium nitrate ingestion $(10 \mathrm{mg} / \mathrm{kg}$ ) and use of antibacterial mouthwash (chlorhexidine $0.2 \%)$.

Results: In tracheostomised subjects oral $\mathrm{FE}_{\mathrm{NO}}$ increased by $90 \%(\mathrm{p}<0.01)$ while tracheal $\mathrm{FE}_{\mathrm{NO}}$ was not affected 60 minutes after nitrate ingestion. Oral EBC nitrite levels were increased 23 -fold at 60 minutes $(p<0.001)$ whereas the nitrite levels in tracheal EBC showed only a minor increase (fourfold, $p<0.05)$. Nitrate was increased the same amount in oral and tracheal $E B C$ at 60 minutes (2.5-fold, $p<0.05$ ). In non-tracheostomised subjects oral $\mathrm{FE}_{\mathrm{NO}}$ and $\mathrm{EBC}$ nitrite increased after nitrate ingestion and after chlorhexidine mouthwash they approached baseline levels again $(p<0.001)$. Nasal NO, nitrate, and nitrite were not affected by nitrate intake or mouthwash. At baseline, mouthwash with deionised water did not affect nitrite in oral EBC or saliva, whereas significant reductions were seen after antibacterial mouthwash ( $p<0.05$ and $p<0.001$, respectively).

Conclusions: Besides the salivary glands, plasma nitrate is taken up by the lower airways but not the nasal airways. Nitrate levels in EBC are thus influenced by dietary intake. Nitrate is reduced to nitrite by bacterial activity which takes place primarily in the oropharyngeal tract of healthy subjects. Only oropharyngeal nitrite seems to contribute to exhaled NO in non-inflamed airways, and there is also a substantial contribution of nitrite from the oropharyngeal tract during standard collection of EBC.
$\mathrm{N}$ itric oxide $(\mathrm{NO})$ is present in exhaled air of animals and humans, ${ }^{1}$ and a number of respiratory diseases characterised by airway inflammation have been associated with altered levels of exhaled NO. ${ }^{2}$ It is, for example, well known that the exhaled NO concentration is increased in asthma. ${ }^{3}$ However, the opposite has been shown in studies of exhaled NO in patients with cystic fibrosis $(\mathrm{CF})^{45}$ and primary ciliary dyskinesia (PCD). ${ }^{67}$ The increase in exhaled NO in asthma has been suggested to be due to an increased expression of inducible NO synthase (iNOS) in the bronchial epithelium, ${ }^{8}$ whereas patients with $\mathrm{CF}$ seem to express less iNOS in the airways than healthy subjects.'

In the oral cavity, $\mathrm{NO}$ is also formed via bacterial reduction of salivary nitrate to nitrite, mainly in the deep crypts in the posterior part of the tongue and subsequently via further chemical reduction of nitrite to NO. ${ }^{10-12}$ Thus, nitrite in the upper airways may serve an important host defence purpose, being a substrate for NO formation. ${ }^{13}$ Also, the nitrite-derived NO in the oropharyngeal tract has been shown to influence NO measurements in exhaled air. ${ }^{11}$ Although most studies on non-invasive markers of airway inflammation have focused on exhaled NO, there has recently been an increasing interest in measuring compounds found in exhaled breath condensate (EBC) ${ }^{.4}$ Exhaled breath is saturated with water vapour that can be condensed by cooling. Exhaled breath also contains water droplets and available evidence suggests that non-volatile substances can be transported from the respiratory tract dissolved in these droplets. ${ }^{15}$ Several non-volatile compounds have been reported to be found in $\mathrm{EBC}$, including nitrite and nitrate. These nitrogen oxides, when found in EBC, have been proposed to be oxidised metabolites of NO primarily and, as such, markers for airway inflammation. ${ }^{16}$ However, the origin of markers in EBC has not yet been sufficiently studied. Furthermore, the increased $^{17}$ or unchanged ${ }^{18}$ levels of nitrite in EBC of patients with CF and PCD, respectively, speak against a direct relation between the level of NO in exhaled air and nitrite in EBC.

To elucidate the origin of nitrate and nitrite in $\mathrm{EBC}$ and to study the possible formation of nitrite from nitrate and NO from nitrite in the respiratory epithelium of the lower and upper airways isolated from the oropharyngeal tract, $\mathrm{NO}$ was measured and EBC collected during tracheal and oral exhalations in patients with a permanent tracheostomy and NO was measured and condensate collected from the nasal airways in non-tracheostomised subjects. These measurements were repeated before and after ingestion of nitrate and mouthwash with an antibacterial agent to manipulate the concentration of nitrite and nitrate in the airways.

\section{METHODS}

\section{NO measurements}

Exhaled NO measurements (fraction of expired $\mathrm{NO}$ at an exhalation flow rate of $50 \mathrm{ml} / \mathrm{s} ; \mathrm{FE}_{\mathrm{NO}}$ ) were made by chemiluminescence according to ATS guidelines. ${ }^{19}$ The

Abbreviations: $\mathrm{EBC}$, exhaled breath condensate; $\mathrm{FE}_{\mathrm{NO}}$, fraction of expired nitric oxide; $\mathrm{CF}$, cystic fibrosis; $\mathrm{PCD}$, primary ciliary dyskinesia; $\mathrm{NO}$, nitric oxide; $\mathrm{dH}_{2} \mathrm{O}$, deionised water 
subjects were asked to inhale NO-free air. After inhalation they immediately exhaled with a target flow rate of $50 \mathrm{ml} / \mathrm{s}$ against a resistance, giving rise to an oral or tracheal pressure of $8-15 \mathrm{~cm} \mathrm{H}_{2} \mathrm{O}$, for a period of 6-10 seconds. The exhaled air was led into the Aerocrine NO System or Niox (Aerocrine AB, Solna, Sweden) for measurement of NO. Nasal NO was measured by aspirating air $(5 \mathrm{ml} / \mathrm{s})$ from one nostril during a breath hold period of at least 20 seconds and the NO plateau was registered (Niox). Ambient NO levels were below $10 \mathrm{ppb}$ during nasal NO measurements.

\section{Condensate collection}

EBC was collected orally or from the tracheostomy (tracheal EBC) using a specifically designed condenser (EcoScreen; Jaeger, Würzburg, Germany). The subjects were asked to breathe at normal frequency and tidal volume while wearing a nose clip. To standardise the collection we used a spirometer with the total exhaled volume set to 20 litres (SpiroPro+; Jaeger, Würzburg, Germany) which took 2-3 minutes. The condenser tube was centrifuged for l-2 minutes at $400 \mathrm{~g}$ at $+4^{\circ} \mathrm{C}$ before aliquoting the condensate. To avoid nitrite/nitrate contamination and to improve the Teflon coating on the condenser tubes, we deposited a Teflon-like coating by means of plasma polymerisation on the existing coating (in-house method at Institute for Surface Chemistry, Stockholm, Sweden). The plasma treated condenser tubes were thoroughly cleaned between all condensate samplings in a slightly acidic desinfectant (Descogen; Jaeger) using ultrasound. The absence of contaminating nitrite/nitrate on condenser tube surfaces after this cleaning procedure was confirmed by rotating tubes end over end with $1 \mathrm{ml}$ nitrate-free and nitrite-free deionised water $\left(\mathrm{dH}_{2} \mathrm{O}\right)$ for 15 minutes and then analysing the content of nitrate and nitrite. This resulted in nitrate concentrations of $<1 \mu \mathrm{M}$ and nitrite concentrations of $<0.2 \mu \mathrm{M}$ after cleaning of plasma treated condenser tubes (used in this study), which was not always the case in non-plasma treated condenser tubes after cleaning.

\section{Nasal condensate collection}

Nasal condensate collection was introduced as a new technique. The subjects were asked to hold their breath and to voluntarily close the velum for 30 seconds while an air

\begin{tabular}{|c|c|c|c|c|c|}
\hline $\begin{array}{l}\text { Patient } \\
\text { no }\end{array}$ & Age & Sex & Cannula & Disorder & Study \\
\hline 1 & 65 & $M$ & Silver & Scoliosis & $\mathrm{FE}_{\mathrm{NO}}$ \\
\hline 2 & 58 & $\mathrm{~F}$ & Silicon & Post-polio & $\mathrm{FE}_{\mathrm{NO}} / \mathrm{EBC}$ \\
\hline 3 & 48 & $\mathrm{~F}$ & Silicon & Post-polio & $\mathrm{FE}_{\mathrm{NO}}$ \\
\hline 4 & 44 & $M$ & Silver/Shiley & Vocal cord palsy & $\mathrm{FE}_{\mathrm{NO}}$ \\
\hline 5 & 60 & $M$ & Shiley & Post-stroke & $\mathrm{FE}_{\mathrm{NO}}$ \\
\hline 6 & 66 & $\mathrm{~F}$ & Silver & Post-polio & $\mathrm{FE}_{\mathrm{NO}} / \mathrm{EBC}$ \\
\hline 7 & 54 & $\mathrm{~F}$ & Silicon & Scoliosis & $\mathrm{FE}_{\mathrm{NO}} / \mathrm{EBC}$ \\
\hline 8 & 66 & $\mathrm{~F}$ & Silver & Scoliosis & $\mathrm{FE}_{\mathrm{NO}} / \mathrm{EBC}$ \\
\hline 9 & 24 & $M$ & Shiley & Post-encephalitis & $\mathrm{FE}_{\mathrm{NO}} / \mathrm{EBC}$ \\
\hline 10 & 67 & $M$ & Shiley & Post-polio & $\mathrm{FE}_{\mathrm{NO}} / \mathrm{EBC}$ \\
\hline 11 & 68 & M & PVC & Idiopathic scoliosis & $\mathrm{EBC}$ \\
\hline 12 & 59 & M & PVC & $\begin{array}{l}\text { Central sleep } \\
\text { apnoea syndrome }\end{array}$ & $\mathrm{EBC}$ \\
\hline 13 & 73 & $\mathrm{~F}$ & Silver & Post-polio & $\mathrm{EBC}$ \\
\hline 14 & 69 & $M$ & Silver & Post-polio & $\mathrm{EBC}$ \\
\hline 15 & 68 & $\mathrm{~F}$ & Silver & Post-polio & $\mathrm{EBC}$ \\
\hline 16 & 51 & $M$ & PVC & Post-polio & $\mathrm{EBC}$ \\
\hline 17 & 35 & M & Silicon & $\begin{array}{l}\text { Neuromuscular } \\
\text { scoliosis }\end{array}$ & $\mathrm{EBC}$ \\
\hline
\end{tabular}

$\mathrm{NO}$, nitric oxide; $\mathrm{FE}_{\mathrm{NO}}$, fraction of expired $\mathrm{NO}$; $\mathrm{EBC}$, exhaled breath condensate.
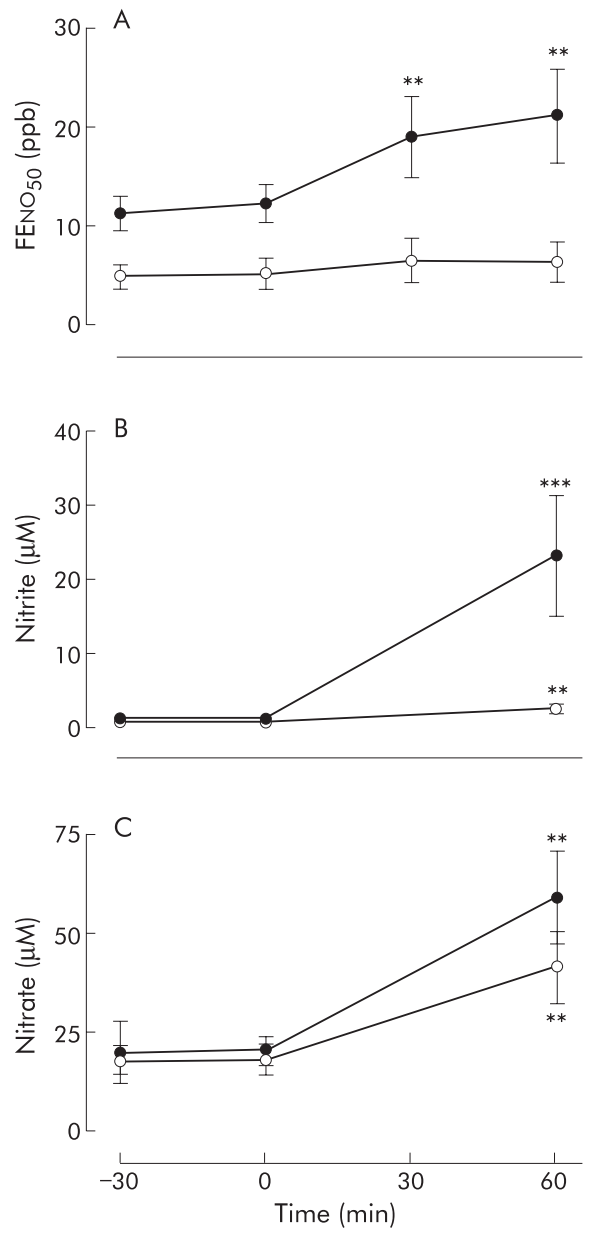

Figure 1 Effects of nitrate ingestion (10 $\mathrm{mg} / \mathrm{kg}$ body weight at $0 \mathrm{~min}$ ) on (A) FE $\mathrm{NO}_{\mathrm{NO}}$ values, (B) nitrite and (C) nitrate concentrations in oral (filled circles) and tracheal (open circles) exhaled breath condensates in tracheostomised patients $(n=10-13)$. ${ }^{* *} p<0.01,{ }^{* * *} p<0.001$ compared with baseline ( $0 \mathrm{~min}$; Wilcoxon test).

stream with a flow rate of $80 \mathrm{ml} / \mathrm{s}$ was led through the nose from one nostril to the other via the introduction of nasal olives and then into the condenser (EcoScreen). This was repeated six times in alternating directions. All condensate samples were immediately frozen and stored at $-80^{\circ} \mathrm{C}$ $(\leqslant 3$ weeks) for later analysis.

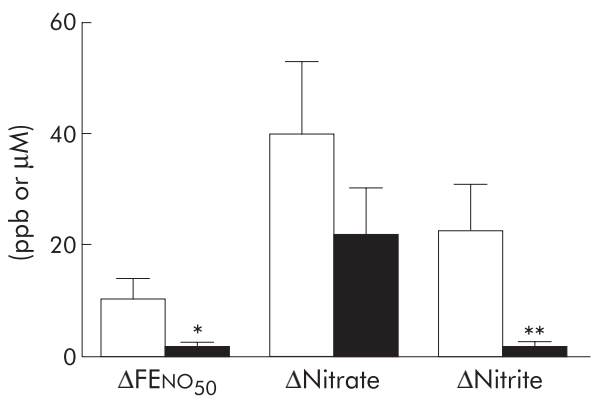

Figure 2 Absolute increase in $\mathrm{FE}_{\mathrm{NO}}$, nitrate, and nitrite in exhaled breath condensate during oral (open bars) and tracheal (filled bars) sampling 60 minutes after nitrate ingestion $(10 \mathrm{mg} / \mathrm{kg}$ body weight) in tracheostomised subjects $(n=10-13)$. ${ }^{*} p<0.05,{ }^{* *} p<0.01$ (Wilcoxon test). 
Table 2 Baseline (fasting) values (mean of two consecutive measurements for each subject) for NO output ( $\mathrm{n} / \mathrm{min}$ ) and nitrate and nitrite in condensate and saliva $(\mu M)$

\begin{tabular}{|c|c|c|c|c|c|}
\hline & \multirow{2}{*}{$\frac{\text { Gas }}{\text { NO output }}$} & \multicolumn{2}{|l|}{ Condensate } & \multicolumn{2}{|l|}{ Saliva } \\
\hline & & Nitrate & Nitrite & Nitrate & Nitrite \\
\hline $\begin{array}{l}\text { Tracheoston } \\
\text { Oral } \\
\text { Tracheal }\end{array}$ & $\begin{array}{l}36.3(5.9) \\
17.6(4.2)^{* \star}\end{array}$ & $\begin{array}{l}19.3(3.4) \\
19.5(3.4)\end{array}$ & $\begin{array}{l}1.1(0.2) \\
0.5(0.1)^{*}\end{array}$ & $606(224)$ & 91 (19) \\
\hline $\begin{array}{l}\text { Non-trache } \\
\text { Oral } \\
\text { Nasal }\end{array}$ & $\begin{array}{l}53.2(5.8) \dagger \dagger \\
285(24)^{* * *}\end{array}$ & $\begin{array}{l}20.0(3.6) \\
25.4(4.9)\end{array}$ & $\begin{array}{l}3.4(0.2) \mathrm{t \dagger \dagger} \\
2.1(0.4)^{*}\end{array}$ & 1318 (226)tt & $252(90) \dagger$ \\
\hline
\end{tabular}

${ }^{*} p<0.05,{ }^{* *} p<0.01,{ }^{* * *} p<0.001$ compared with oral values in the same subjects (Wilcoxon test).

$\mathrm{t} p<0.05, \mathrm{t} \mathrm{p}<0.01,+t \mathrm{t}<0.001$ compared with values in tracheostomised subjects (Mann-Whitney test).

\section{Saliva collection}

The subjects were asked to chew on a small piece of plastic for 1 minute and saliva $(1-2 \mathrm{ml})$ was collected in a tube, centrifuged for 10 minutes at $400 \mathrm{~g}$ at $+4^{\circ} \mathrm{C}$ and the supernatant was stored at $-80^{\circ} \mathrm{C}$ for later analysis.

\section{Analyses}

For analysis of nitrite/nitrate and amylase, commercially available kits were used: Nitrate/Nitrite Fluorometric Assay kit; Cayman Chemical Company, Ann Arbor, MI, USA (detection limit $0.2 \mu \mathrm{M}$ ) and EnzChek Amylase Assay Kit; Molecular Probes Inc, Eugene, OR, USA (detection limit $0.1 \mathrm{IU} / \mathrm{l}$ corresponding to $0.3 \mathrm{ng} / \mathrm{l}$ protein).

\section{Subjects}

A total of 17 subjects with a permanent tracheostomy attending the Respiratory Unit at Danderyd Hospital, a national center for tracheostomised patients in Sweden, were recruited for the first two studies (table 1). All patients had tracheal cannula systems allowing them to breathe either via the mouth with the tracheal cannula plugged or via the tracheostomy with the upper airway sealed off. Their respiratory failure was extrapulmonary and none of them had a pulmonary disease. However, in some of the patients the upper part of the trachea was colonised by bacteria such as Pseudomonas aeruginosa, Streptococcus pneumoniae, Staphylococcus aureus, Proteus mirabilis, Streptococcus $(B, G)$ and/or Enterobacter cloacace. Fifteen healthy non-tracheostomised controls aged 24-44 years (seven men) were recruited for the third and fourth study. All subjects were non-smokers and had no history of allergy or chronic pulmonary disease. They did not have any ongoing respiratory infection.

The studies were approved by the local ethics committee and all subjects gave informed consent.

\section{Orally and tracheally exhaled NO in tracheostomised patients}

Ten tracheostomised patients had fasted overnight and the experiments were performed in the morning. Baseline values of oral and tracheal $\mathrm{FE}_{\mathrm{NO}}$ were measured using the Aerocrine NO system 30 minutes and immediately before sodium

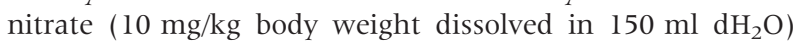
was ingested. This nitrate intake corresponds to approximately $200 \mathrm{~g}$ greenhouse lettuce in a $70 \mathrm{~kg}$ person. ${ }^{20}$ The mouth was rinsed with tap water immediately after the nitrate intake. Measurements of $\mathrm{FE}_{\mathrm{NO}}$ were then repeated at 30, 60 and 90 minutes after the nitrate load. Samples of saliva were taken at the same time points, directly after NO measurements.

\section{Nitrate and nitrite in tracheal and oral EBC in tracheostomised patients}

Thirteen tracheostomised patients had fasted overnight and, after two baseline collections ( -30 and 0 minutes), all subjects ingested sodium nitrate as above and oral and tracheal EBC were collected 60 minutes thereafter.

\section{Orally exhaled and nasal NO, nitrate and nitrite in non-tracheostomised healthy subjects}

Thirteen non-tracheostomised healthy subjects had fasted overnight and measurements of nasal $\mathrm{NO}$ and oral $\mathrm{FE}_{\mathrm{NO}}$ were made and collection of oral EBC, nasal condensate, and saliva were performed before ( -30 and 0 minutes) and 60 minutes after a nitrate load as described above. Nasal NO and oral $\mathrm{FE}_{\mathrm{NO}}$ measurements were made using the Niox system and oral EBC and nasal condensate were collected as described above. At 65 minutes after nitrate ingestion, directly after the 60 minute sampling, the subjects were asked to rinse their mouths with an antibacterial mouthwash solution $(25 \mathrm{ml}$ $0.2 \%$ chlorhexidine diacetate with $0.01 \%$ menthol) for

Table 3 Salivary nitrite and nitrate concentrations $(\mu \mathrm{M})$ before and after nitrate ingestion and 5 minutes after chlorhexidine mouthwash

\begin{tabular}{|c|c|c|c|c|c|}
\hline & \multicolumn{4}{|c|}{ Time (minutes) } & \multirow[b]{2}{*}{ Mouthwash } \\
\hline & -30 & 0 & 30 & 60 & \\
\hline \multicolumn{6}{|c|}{ Tracheostomised subjects } \\
\hline Nitrite & 135 (33) & $64(12)$ & $860(244)^{\star *}$ & $1093(220)^{* *}$ & ND \\
\hline Nitrate & 407 (99) & $806(424)$ & $7397(1748)^{\star *}$ & $9596(1831)^{\star *}$ & ND \\
\hline \multicolumn{6}{|c|}{ Non-tracheostomised subjects } \\
\hline Nitrite & $150(31)$ & $236(91)$ & ND & $1263(282)^{\star *}$ & $353(75) \dagger+\uparrow$ \\
\hline Nitrate & $1348(228)$ & $1288(229)$ & ND & $10852(1198)^{* *}$ & $10397(1361)^{* *}$ \\
\hline
\end{tabular}

ND, not determined.

${ }^{* *} p<0.01$ compared with before nitrate ingestion (0 minutes).

$\dagger+\uparrow p<0.001$ compared with before mouthwash (60 minutes) 
Table 4 Nasal NO levels (ppb) and nitrite and nitrate in nitrate condensate $(\mu M)$ before and after nitrate ingestion and 5 minutes after chlorhexidine mouthwash

\begin{tabular}{lllll}
\hline & \multicolumn{2}{l}{ Time (minutes) } & & \\
\cline { 2 - 4 } & $-\mathbf{3 0}$ & $\mathbf{0}$ & $\mathbf{6 0}$ & Mouthwash \\
\hline NO & $905(78)$ & $952(78)$ & $897(94)$ & $960(78)$ \\
Nitrite & $1.7(0.3)$ & $1.8(0.3)$ & $2.3(0.5)$ & $3.3(0.8)$ \\
Nitrate & $21.5(4.8)$ & $29.6(7.2)$ & $23.7(6.6)$ & $18.3(5.2)$ \\
\hline
\end{tabular}

No significant changes were seen (Friedman).

30 seconds and all measurements were repeated after 5 minutes.

\section{Oral and salivary nitrate and nitrite after different mouthwash procedures}

Oral EBC and saliva were collected from 15 healthy subjects before and 5 minutes after mouthwash with $\mathrm{dH}_{2} \mathrm{O}(25 \mathrm{ml})$ for 30 seconds, and subsequently 5 minutes after mouthwash with chlorhexidine as described above.

\section{Statistical analysis}

NO output was calculated as: [NO] $(\mathrm{ppb}$ or $\mathrm{nl}) \times \dot{\mathrm{V}}(\mathrm{l} / \mathrm{min})$ $=\mathrm{nl} / \mathrm{min}$. This was done to enable comparison between nasal and lower airway NO production. Baseline values for $\mathrm{NO}$ output and nitrite and nitrate in EBC and saliva were calculated as the mean of two repeated samples $(-30$ and 0 minutes). All results are presented as mean (SE). The Mann-Whitney test, the Wilcoxon signed rank test, and the Spearman rank correlation test were used as indicated. If there were more than two repeated measures, a significant Friedman test was a prerequisite before further testing with Wilcoxon. All calculations were made using the Prism software Version 4 (Graphpad Software Inc, San Diego, CA, USA).

\section{RESULTS}

\section{Oral $v$ tracheal comparisons in tracheostomised subjects}

At baseline, mean NO output was approximately twice as high during oral exhalation as during tracheal exhalation (table 2). After nitrate ingestion, oral $\mathrm{FE}_{\mathrm{NO}}$ increased steadily to a maximum at 60 minutes (fig $1 \mathrm{~A}$ ). NO output had then increased by almost $90 \%$ compared with baseline levels. At 90 minutes oral $\mathrm{FE}_{\mathrm{NO}}$ had started to return to baseline levels (17 (2.8) ppb at 90 minutes) but was still significantly increased $(\mathrm{p}<0.05$, Wilcoxon test). No significant change in the amount of NO exhaled from the tracheostomy was seen during the total observation period of 90 minutes after nitrate ingestion. The nitrate concentration in the saliva showed a maximal 12 -fold increase at 60 minutes (table 3 ) and the nitrite concentration showed a maximal 18 -fold

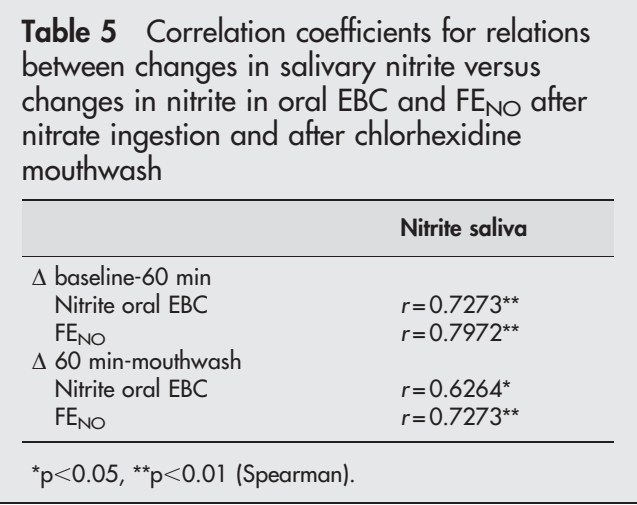

increase at 90 minutes (1167 (289) $\mu \mathrm{M}$ ) after nitrate ingestion. The condensate yield was 18 (1) $\mu \mathrm{l} / \mathrm{l}$ exhaled air during oral condensate sampling (not different from non-tracheostomised subjects, see below) and 14 (1) $\mu \mathrm{l} / \mathrm{l}$ during tracheal sampling $(\mathrm{p}<0.05$, Wilcoxon test $)$. Baseline nitrate concentrations were similar in oral and tracheal EBC, whereas nitrite concentrations were approximately twice as high in oral EBC as in tracheal EBC (table 2). At 60 minutes the nitrate concentration had increased in both oral and tracheal EBC by $284 \%$ and $214 \%$, respectively (fig 1C). The absolute increase in nitrate was of a similar magnitude in oral and tracheal EBC (fig 2). There was a 23-fold increase in nitrite concentration in oral EBC 60 minutes after the nitrate load and a fourfold increase in tracheal EBC at the same time point (fig $1 \mathrm{~B}$ ). The absolute increase in $\mathrm{FE}_{\mathrm{NO}}$ was fivefold higher and the increase in EBC nitrite was 12-fold higher during oral exhalation compared with tracheal exhalation (fig 2). Interestingly, salivary levels of nitrate and nitrite as well as nitrite in oral EBC and NO output were all significantly lower in tracheostomised subjects than in nontracheostomised subjects (table 2). All these differences had disappeared 60 minutes after nitrate ingestion.

\section{Oral $v$ nasal comparisons in non-tracheostomised subjects}

Baseline mean NO output was approximately fivefold higher in the nasal airways than in the lower airways (table 2). Oral $\mathrm{FE}_{\mathrm{NO}}$ increased as expected after the nitrate load (from 17.7 (1.9) ppb at 0 minutes to 26.7 (2.5) ppb at 60 minutes; $\mathrm{p}<0.001$, Wilcoxon). However, nasal NO levels were not affected by nitrate ingestion (table 4). Nitrite in saliva showed an expected ninefold increase 60 minutes after nitrate ingestion (table 3). Nasal condensate yield was 26 (1) $\mu \mathrm{l} / \mathrm{l}$ air which was significantly higher than for oral EBC (18 (1) $\mu \mathrm{l} / \mathrm{l} ; \mathrm{p}<0.01$, Wilcoxon test). Baseline levels of nitrate were similar in nasal condensate and oral EBC, whereas the mean nitrite concentration was $60 \%$ higher in oral EBC than in nasal condensate (table 2). After nitrate ingestion there was a fivefold increase in nitrite concentration in oral EBC at 60 minutes (from $3.5(0.7) \mu \mathrm{M}$ at 0 minutes to 17.8 (3.4) $\mu \mathrm{M}$ at 60 minutes; $p<0.001$, Wilcoxon test), similar to findings in the tracheostomised subjects (see above). However, nitrate and nitrite concentrations in nasal condensate did not change after the nitrate load (table 4). The increase in $\mathrm{FE}_{\mathrm{NO}}$ and the increase in nitrite concentration in oral EBC both correlated with the increase in salivary nitrite levels (table 5).

\section{Evaluation of antibacterial mouthwash}

Mouthwash with deionised water did not change the levels of nitrate or nitrite in saliva or oral EBC (table 6). In contrast, chlorhexidine mouthwash significantly reduced nitrite levels in saliva and oral EBC while nitrate levels remained unaffected. Sixty minutes after a nitrate load, antibacterial mouthwash reduced oral $\mathrm{FE}_{\mathrm{NO}}$ in all subjects (mean reduction 20\%; fig $3 \mathrm{~A}$ ) but it was still higher than baseline, whereas nitrite levels in oral EBC were restored to baseline 

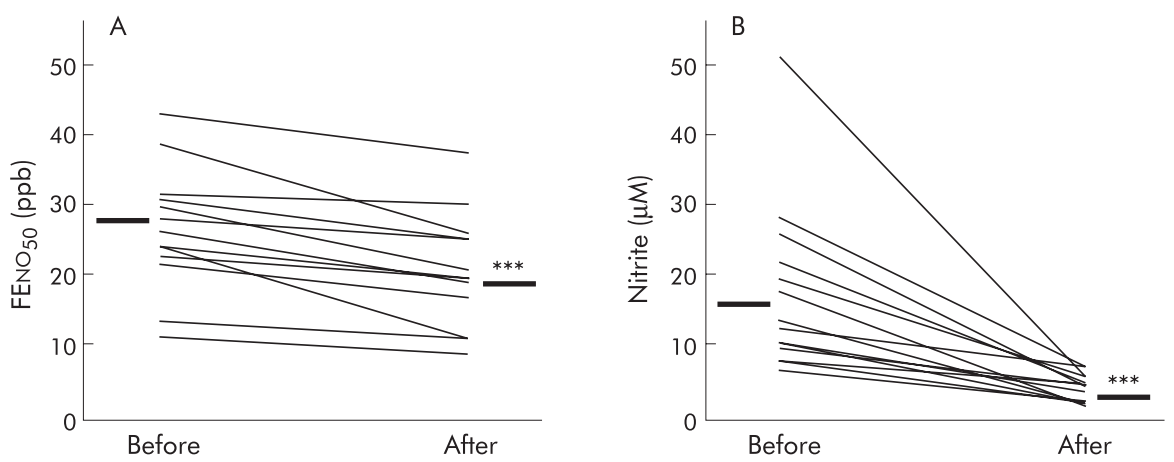

Figure 3 Effect of antibacterial mouthwash (chlorhexidine $0.2 \%$ ) given 60 minutes after nitrate ingestion on $(A)$ oral $F E_{N O}$ values and (B) oral $E B C$ nitrite levels in non-tracheostomised subjects $(n=13) .{ }^{* * *} p<0.001 v$ before mouthwash (Wilcoxon test).

levels by the mouthwash (mean reduction $81 \%$; fig $3 \mathrm{~B}$ ). Nitrate levels in EBC were not affected by chlorhexidine (not shown). The reduction in $\mathrm{FE}_{\mathrm{NO}}$ and nitrite levels in oral $\mathrm{EBC}$ by chlorhexidine both correlated with the reduction in salivary nitrite levels (table 5). Amylase activity was not detected in any of the condensate samples from either tracheostomised or non-tracheostomised subjects, whereas high amylase activity was noted in saliva samples (>5000 IU/1).

\section{DISCUSSION}

We have confirmed that orally exhaled NO is only partly derived from the airways below the upper trachea in respiratory healthy subjects, and that there is a significant contribution of NO from the oropharynx formed via the reduction of nitrite in saliva. We have been able to extend the knowledge on nitrite derived NO formation in the airways by sampling from the lower or nasal airways, isolated from the oropharyngeal tract, before and after ingestion of nitrate. Furthermore, we have studied the possible oropharyngeal contribution of nitrite and nitrate in oral EBC using a standard technique.

After ingestion, nitrate is rapidly absorbed in the gastrointestinal tract and the plasma concentration increases. ${ }^{1021}$ Nitrate is then actively taken up by the salivary glands in a plasma concentration dependent way and salivary nitrate concentrations increase also. ${ }^{10}$ In the oral cavity facultative anaerobic bacteria in the deep crypts of the base of the tongue reduce nitrate to nitrite in the course of respiration and, thus, salivary nitrite levels are also increased..$^{10-12}$ Some of this nitrite is reduced to NO in the oral cavity which contributes to levels of $\mathrm{NO}$ measured in exhaled breath. ${ }^{112}$ Our data indicate that nitrate is also taken up directly from the circulation by the lower airways since nitrate concentrations were increased in the tracheal EBC of our tracheostomised subjects 1 hour after nitrate ingestion. The increase in the lower airways may be explained by passive diffusion from plasma. This would be in line with previous studies in which the distribution volume for nitrate was found to be large (approximately $30 \%$ of body weight). ${ }^{22}$

Experiments with radioactively labelled nitrate have shown that a substantial part of the ingested radioactive nitrogen cannot be recovered in faeces or urine. ${ }^{23}$ One explanation is that the lost nitrate undergoes metabolism to gaseous products and is exhaled in the breath as, for example, NO. ${ }^{11}$ We show here that some of the ingested nitrate is excreted in the respiratory tract also by aerosolisation of airway epithelial lining fluid and saliva. Interestingly, the airway mucosal uptake of nitrate from plasma seems to be restricted to the lower airways since nitrate levels in nasal condensate were not affected by a nitrate load.

We did not see a change in nitrite concentration in nasal condensate after nitrate ingestion, which indicates that we did not have any contamination from the pharynx during nasal condensate collection with our method. Others have collected breath condensate from the nose during normal tidal breathing ${ }^{24}$ but, if such a method is used, the origin of the collected fluid will be a mixture of the lower airways, pharynx, and the nasal airways.

Although nitrite levels in nasal condensate were unchanged, we found a significant increase in the nitrite concentration in tracheal condensate after the nitrate load. This increase may not rely on passive diffusion from the circulation since the plasma nitrite concentration is usually very low and is not readily increased to high concentrations by nitrate ingestion. It is well known that nitrite is rapidly oxidised to nitrate in the presence of oxyhaemoglobin. Instead, the increase in lower airway nitrite may be due to xanthine oxidase activity in the pulmonary epithelium ${ }^{25} 26$ or bacterial activity in the trachea of tracheostomised subjects. Patients with a permanent tracheal cannula are often colonised by bacteria ${ }^{27}$ such as Pseudomonas aeruginosa, both in the trachea and in biofilm formation on the cannula tube. $^{28} P$ aeruginosa is capable of reducing nitrate to nitrite both under anaerobic and aerobic conditions. ${ }^{29}$ Thus, bacterial activity could be a reason for the increased nitrite

Table 6 Levels of nitrite and nitrate $(\mu M)$ in oral EBC and saliva before and after mouthwash with deionised water and chlorhexidine

\begin{tabular}{|c|c|c|c|}
\hline & Baseline & $\mathrm{dH}_{2} \mathrm{O}$ & Chlorhexidine \\
\hline \multicolumn{4}{|c|}{ Exhaled breath condensate } \\
\hline Nitrite & $2.8(0.5)$ & $3.0(0.9)$ & $2.0(0.4)^{\star}$ \\
\hline Nitrate & $24.9(5.1)$ & $28.7(4.9)$ & $29.6(8.6)$ \\
\hline \multicolumn{4}{|l|}{ Saliva } \\
\hline Nitrite & $182(34)$ & $140(26)$ & $79.3(17)^{\star * *}$ \\
\hline Nitrate & $415(82)$ & 367 (77) & $429(84)$ \\
\hline
\end{tabular}


concentration seen in tracheal EBC in our tracheostomised subjects. However, no relation between the presence of $P$ aeruginosa (or any of the other bacteria detected in our sample of tracheostomised subjects) and the level of nitrite or nitrate in tracheal EBC could be found. Interestingly, the tracheostomised subjects had lower baseline levels of nitrite and nitrate in saliva, nitrite in oral EBC, and exhaled NO than non-tracheostomised subjects. These differences could be due to the lower nitrate content in saliva, indicating an altered saliva production or nitrate uptake in the tracheostomised subjects or, alternatively, an altered bacterial activity in the oropharyngeal tract. If this is due to the tracheostomy, the higher age in this group or other causes is not known.

In this study we have shown that changes in salivary nitrite levels correlate with changes in exhaled NO and nitrite in oral EBC, both after nitrate ingestion and chlorhexidine mouthwash. Thus, nitrite in saliva is an important contaminant for EBC collections as well as for exhaled NO measurements. ${ }^{1121}$ Indeed, the maximal oropharyngeal influence on EBC nitrite levels is of much greater magnitude than that on exhaled NO. A reduction of nitrite in saliva and oral EBC was seen after mouthwash with chlorhexidine but not with deionised water, similar to earlier findings for exhaled NO. ${ }^{11}$ Nitrate levels were not affected by chlorhexidine which is a potent antibacterial agent with well documented effects in the oral cavity. ${ }^{30}$ Together these data clearly indicate that nitrite formation in the saliva-and thus the levels found in oral EBC-are dependent on bacterial activity in the oropharyngeal tract. Several groups have reported that the nitrite and/or nitrate concentration in EBC is increased in airway diseases, particularly asthma and $\mathrm{CF}^{16}{ }^{17^{31-34}}$ and the general postulate has been that the measured levels of nitrite and nitrate are oxidation products of NO. Our results show that both nitrite and nitrate levels in the lower airways can also increase after nitrate ingestion, and an antibacterial mouthwash reduces the presence of nitrite in EBC. Thus, nitrite in EBC may primarily be a marker of oropharyngeal bacterial activity and not a marker of NO formation and airway inflammation. However, in pneumonia induced acute lung injury, nitrite formation also seems to increase in the lower airways below the tracheal tube, ${ }^{35}$ but these conditions are rarely connected with increases in exhaled NO indicating that this nitrite is also of bacterial origin. After cigarette smoking (tobacco smoke contains high amounts of NO) only nitrate and not nitrite seems to be increased in EBC. ${ }^{36}{ }^{37}$ Although these studies indicate that nitrate in EBC may be related to the presence of NO, further studies are needed to elucidate the relation between the formation of NO, nitrite, and nitrate in the lower airways in health and disease where nitrite and nitrate should be analysed and reported separately.

It has been suggested that NO formation from nitrite in the lower airways could contribute to exhaled NO levels in acute inflammation when the $\mathrm{pH}$ in the airways is reduced. ${ }^{38}$ However, we found substantial amounts of nitrite derived $\mathrm{NO}$ formation from the saliva where the $\mathrm{pH}$ is usually close to 7 (between 6 and 8), while no such NO formation could be detected in the lower airways below the upper trachea. The reduction of nitrite to NO may also be enhanced by the presence of reducing agents-for example, ascorbate ${ }^{11}{ }^{39}$ and it is thus suggested that the presence of such agents may be the dominating factor controlling the reduction of nitrite at a neutral $\mathrm{pH}$. Some bacteria are also able to reduce nitrite to NO. ${ }^{29}$ However, commensal bacteria very rarely use this denitrifying pathway but instead use a short cut resulting in the formation of ammonia. ${ }^{40}$

We have shown that the oropharyngeal tract contributes substantially to nitrite and, to some extent, nitrate in EBC collected in a standardised way, and the condensate yield was higher during oral than tracheal normal tidal breathing. This was seen in spite of the fact that amylase activity was not detected in the samples which, in turn, shows that measurements of amylase activity are not adequate to rule out contamination from the oropharyngeal tract. Our findings indicate that a significant portion of respiratory droplets ${ }^{15}$ that "survive" all the way beyond the lips during exhalation are formed in the very proximal airways including the oropharyngeal tract. Respiratory droplets are most likely formed also in the peripheral airways ${ }^{41}$ but it is not known what proportion of these peripheral droplets actually travel all the way to the exterior during exhalation without being deposited more centrally in the airways.

We conclude that plasma nitrate is taken up by the salivary glands and the lower airways but not by the nasal airways. Nitrite formation from nitrate in the human respiratory tract is confined to the oropharyngeal tract and trachea and probably involves bacterial activity. The further reduction of nitrite to NO is restricted to the oropharynx, at least in our subjects without inflammatory airway disease. Another significant finding is that a major part of the nitrite found in EBC originates in the oropharyngeal tract above the upper trachea, indicating proximal generation of respiratory droplets. Nitrate in EBC seems to originate both in the oropharynx and the lower airways but is influenced by plasma levels and thus dietary intake in the form of, for example, green leaved vegetables.

\section{ACKNOWLEDGEMENTS}

The authors gratefully acknowledge Ms Margareta Stensdotter and Mrs Carina Nihlén for their expert technical assistance during the biochemical analyses, and are grateful to Dr Kenth Johansson, Institute for Surface Chemistry, Stockholm, for help with plasma treatment of condenser tubes.

\section{Authors' affiliations}

H Marteus, K Alving, Department of Physiology and Pharmacology, Karolinska Institutet, Stockholm, Sweden

D C Törnberg, E Weitzberg, Department of Surgical Sciences, Karolinska Institutet, Stockholm, Sweden

U Schedin, Division of Anaesthesia and Intensive Care, Danderyd Hospital, Stockholm, Sweden

This study was supported by the Swedish Research Council, Medicine (no 10354), the Swedish Heart-Lung Foundation, the Swedish Asthma and Allergy Association's Research Foundation, the Swedish Knowledge Foundation, Karolinska Institutet and Aerocrine AB.

Competing interests: HM, DCT and US declare no competing interests. KA and EW are co-founders and shareholders of Aerocrine AB. KA has received research funding from Aerocrine. EW is a member of the board of Aerocrine.

\section{REFERENCES}

1 Gustafsson LE, Leone AM, Persson MG, et al. Endogenous nitric oxide is present in the exhaled air of rabbits, guinea pigs and humans. Biochem Biophys Res Commun 1991;181:852-7.

2 American Thoracic Society. Recommendations for standardized procedures for the on-line and off-line measurement of exhaled lower respiratory nitric oxide and nasal nitric oxide in adults and children-1999. Am J Respir Crit Care Med 1999; 160:2104-17.

3 Alving K, Weitzberg E, Lundberg JM. Increased amount of nitric oxide in exhaled air of asthmatics. Eur Respir J 1993;6:1368-70.

4 Lundberg JO, Nordvall SL, Weitzberg E, et al. Exhaled nitric oxide in paediatric asthma and cystic fibrosis. Arch Dis Child 1996;75:323-6.

5 Grasemann H, Michler E, Wallot M, et al. Decreased concentration of exhaled nitric oxide (NO) in patients with cystic fibrosis. Pediatr Pulmonol 1997;24:173-7.

6 Lundberg JO, Weitzberg E, Nordvall SL, et al. Primarily nasal origin of exhaled nitric oxide and absence in Kartagener's syndrome. Eur Respir J 1994;7:1501-4.

7 Karadag B, James AJ, Gultekin E, et al. Nasal and lower airway level of nitric oxide in children with primary ciliary dyskinesia. Eur Respir J 1999; 13:1402-5.

8 Hamid Q, Springall DR, Riveros-Moreno V, et al. Induction of nitric oxide synthase in asthma. Lancet 1993;342:1510-3. 
9 Kelley TJ, Drumm ML. Inducible nitric oxide synthase expression is reduced in cystic fibrosis murine and human airway epithelial cells. J Clin Invest 1998; 102:1200-7.

10 Tannenbaum SR, Weisman M, Fett D. The effect of nitrate intake on nitrite formation in human saliva. Food Cosmet Toxicol 1976;14:549-52.

11 Zetterquist W, Pedroletti C, Lundberg JO, et al. Salivary contribution to exhaled nitric oxide. Eur Respir J 1999;13:327-33.

12 Duncan C, Dougall H, Johnston P, et al. Chemical generation of nitric oxide in the mouth from the enterosalivary circulation of dietary nitrate. Nat Med 1995; 1:546-51.

13 Weitzberg $\mathbf{E}$, Lundberg JO. Nonenzymatic nitric oxide production in humans. Nitric Oxide 1998;2:1-7.

14 Kharitonov SA, Barnes PJ. Biomarkers of some pulmonary diseases in exhaled breath. Biomarkers 2002;7:1-32.

15 Effros RM, Hoagland KW, Bosbous M, et al. Dilution of respiratory solutes in exhaled condensates. Am J Respir Crit Care Med 2002;165:663-9.

16 Hunt J, Byrns RE, Ignarro $\amalg$, et al. Condensed expirate nitrite as a home marker for acute asthma [letter]. Lancet 1995;346:1235-6.

17 Ho LP, Innes JA, Greening AP. Nitrite levels in breath condensate of patients with cystic fibrosis is elevated in contrast to exhaled nitric oxide. Thorax 1998;53:680-4.

18 Csoma Z, Bush A, Wilson NM, et al. Nitric oxide metabolites are not reduced in exhaled breath condensate of patients with primary ciliary dyskinesia. Chest 2003; 124:633-8.

19 Nightingale JA, Rogers DF, Barnes PJ. Effect of inhaled ozone on exhaled nitric oxide, pulmonary function, and induced sputum in normal and asthmatic subjects. Thorax 1999;54:1061-9.

20 Tosun I, Ustun NS. Nitrate content of lettuce grown in the greenhouse. Bull Environ Contam Toxicol 2004;72:109-13.

21 Olin AC, Aldenbratt A, Ekman A, et al. Increased nitric oxide in exhaled air after intake of a nitrate-rich meal. Respir Med 2001;95:153-8.

22 Jungersten L, Edlund A, Petersson AS, et al. Plasma nitrate as an index of nitric oxide formation in man: analyses of kinetics and confounding factors. Clin Physiol 1996;16:369-79.

23 Wagner DA, Schultz DS, Deen WM, et al. Metabolic fate of an oral dose of $15 \mathrm{~N}$-labeled nitrate in humans: effect of diet supplementation with ascorbic acid. Cancer Res 1983;43:1921-5.

24 Latzin P, Beck J, Bartenstein A, et al. Comparison of exhaled breath condensate from nasal and oral collection. Eur J Med Res 2003;8:505-10.

25 Sergeev NS, Ananiadi LI, L'Vov NP, et al. The nitrate reductase activity of milk xanthine oxidase. J Appl Biochem 1985;7:86-92.
26 Kayyali US, Budhiraja R, Pennella CM, et al. Upregulation of xanthine oxidase by tobacco smoke condensate in pulmonary endothelial cells. Toxicol Appl Pharmacol 2003;188:59-68.

27 Harlid R, Andersson G, Frostell CG, et al. Respiratory tract colonization and infection in patients with chronic tracheostomy. $A$ one-year study in patients living at home. Am J Respir Crit Care Med 1996;154:124-9.

28 Jarrett WA, Ribes J, Manaligod JM. Biofilm formation on tracheostomy tubes. Ear Nose Throat J 2002;81:659-61.

29 Hassett DJ, Cuppoletti J, Trapnell B, et al. Anaerobic metabolism and quorum sensing by Pseudomonas aeruginosa biofilms in chronically infected cystic fibrosis airways: rethinking antibiotic treatment strategies and drug targets. Adv Drug Deliv Rev 2002;54:1425-43.

30 Cohen DW, Atlas SL. Chlorhexidine gluconate in periodontal treatment. Compend Suppl. 1994: S711-3; quiz S714-7).

31 Cunningham S, McColm JR, Ho LP, et al. Measurement of inflammatory markers in the breath condensate of children with cystic fibrosis. Eur Respir J 2000;15:955-7.

32 Formanek W, Inci D, Lauener RP, et al. Elevated nitrite in breath condensates of children with respiratory disease. Eur Respir J 2002;19:487-91.

33 Corradi M, Montuschi P, Donnelly LE, et al. Increased nitrosothiols in exhaled breath condensate in inflammatory airway diseases. Am J Respir Crit Care Med 2001; 163:854-8.

34 Ganas K, Loukides S, Papatheodorou G, et al. Total nitrite/nitrate in expired breath condensate of patients with asthma. Respir Med 2001;95:649-54.

35 Gessner C, Hammerschmidt S, Kuhn H, et al. Exhaled breath condensate nitrite and its relation to tidal volume in acute lung injury. Chest 2003; 124: 1046-52.

36 Corradi M, Pesci A, Casana R, et al. Nitrate in exhaled breath condensate of patients with different airway diseases. Nitric Oxide 2003:8:26-30.

37 Balint B, Donnelly LE, Hanazawa T, et al. Increased nitric oxide metabolites in exhaled breath condensate after exposure to tobacco smoke. Thorax 2001;56:456-61

38 Hunt JF, Fang K, Malik R, et al. Endogenous airway acidification. Implications for asthma pathophysiology. Am J Respir Crit Care Med 2000;161:694-9.

39 Lundberg JO, Carlsson S, Engstrand L, et al. Urinary nitrite: more than a marker of infection. Urology 1997;50:189-91.

40 Lundberg JON, Weitzberg E, Cole JA, et al. Nitrate, bacteria and human health. Nature Rev Microbiol 2004;2:593-602.

41 Dwyer TM. Cigarette smoke-induced airway inflammation as sampled by the expired breath condensate. Am J Med Sci 2003;326:174-8.

\section{LUNG ALERT}

Intravenous immunoglobulin improves clinical outcome in Churg-Strauss syndrome

$\Delta$ Danieli MG, Cappelli M, Malcangi G, et al. Long term effectiveness of intravenous immunoglobulin in Churg-Strauss syndrome. Ann Rheum Dis 2004;63:1649-54

$\longrightarrow$ hurg-Strauss Syndrome (CSS) is a necrotising vasculitis of medium and small sized vessels clinically characterised by asthma, eosinophilia, and systemic vasculitis associated with circulating antibodies to antineutrophil cytoplasmic antigen (ANCA). The standard treatment of this condition comprises corticosteroids and, in severe cases, cytotoxic drugs. However, this treatment protocol is associated with a high relapse rate and significant drug dependent side effects.

In this prospective study 18 patients with new onset CSS were evaluated and divided into two groups. While all patients received the standard treatment of prednisolone ( $1 \mathrm{mg} / \mathrm{kg} / \mathrm{day}$ for 1 month and then tapered) and, in severe cases, cyclophosphamide ( $2 \mathrm{mg} / \mathrm{kg} / \mathrm{day}$ for 6 months), nine patients in the treatment group received "synchronized therapy" comprising cycles of plasmapheresis and intravenous immunoglobulin $(2 \mathrm{~g} / \mathrm{kg})$. This was repeated monthly to 6 months, then bi-monthly for another three cycles. All patients were evaluated monthly for 1 year and subsequently followed up for 3 years. At the end of 1 year all nine patients in the treatment group and four in the control group were in remission. At the end of 3 years there was a clinically and statistically significant reduction in disease activity in the treatment group as measured by the Birmingham Vasculitis Activity Score (BVAS) and modified Rankin score. The frequency of relapse was also lower in the treatment group (1/9) compared with the control group (4/9). Finally, the daily maintenance dose of prednisolone required was less in the treatment group, as was the incidence of steroid induced side effects such as osteoporosis.

This study suggests plasmapheresis and intravenous immunoglobulin to be a new yet safe treatment option for CSS as an add-on to the standard treatment protocol. Further studies with larger sample size are needed to confirm the evidence generated by this study.

A Padmanabhan

Consultant Respiratory Physician, S P Fort Hospital, Trivandrum, India; arjun_p@vsnl.com 